\title{
ЭФФЕКТИВНАЯ РЕАЛИЗАЦИЯ ПРАГМАТИЧЕСКОГО ПОТЕНЦИАЛА ЭТНИЧЕСКОЙ ИДЕНТИЧНОСТИ В СИТУАЦИЯХ МЕЖЭТНИЧЕСКОГО ВЗАИМОДЕЙСТВИЯ
}

\author{
И. А. Антипьева', Ю. Г. Липко² \\ ${ }^{1}$ Байкальский государственный университет, г. Иркутск, Российская Федерация \\ 2 Иркутский государственный университет, г. Иркутск, Российская Федерация
}

Информация о статье

Дата поступления

3 мая 2017 г.

Дата принятия к печати 5 июня 2017 г.

Дата онлайн-размещения 15 сентября 2017 г.

\section{Ключевые слова}

Этническая идентичность; ориентирующее воздействие; межличностное взаимодействие;

прагматический потенциал

\begin{abstract}
Аннотация
Проблемы изучения этничности, ее проявления и эволюции относятся к центральным вопросам современных социальных и лингвистических исследований. В связи с тем что «пластичность» признана ведущей характеристикой этнической идентичности, особый интерес представляет изучение прагматического потенциала ситуаций использования этнолексики. В статье рассматриваются контексты, влияющие на изменение поведения отдельных индивидов в ситуациях межличностного и межгруппового взаимодействия, исследуются ситуации, в которых произошла благоприятная для участвующих в коммуникации сторон реализация прагматического потенциала этнических представлений, анализируется ориентирующий потенциал этнолексем. При этом особое внимание уделяется особенностям восприятия собеседниками национальностей друг друга и определению вектора развития этнической идентичности каждой из сторон общения.
\end{abstract}

\section{PRAGMATIC POTENTIAL OF ETHNIC IDENTITY AND ITS EFFECTIVE REALIZATION IN INTERNATIONAL INTERACTION}

\author{
Irina A. Antipieva', Yulia G. Lipko² \\ ${ }^{1}$ Baikal State University, Irkutsk, Russian Federation \\ ${ }^{2}$ Irkutsk State University, Irkutsk, Russian Federation
}

\author{
Article info \\ Received \\ May 3, 2017 \\ Accepted \\ June 5, 2017 \\ Available online \\ September 15, 2017

\section{Keywords} \\ Ethnic identity; ethnonyms; \\ orientational influence; \\ interpersonal encounter; \\ pragmatic potential
}

\begin{abstract}
The issue of personal ethnic identity, its manifestation as well as evolution lies in the very centre of current socio-linguistic researches. The situations in which pejorative and ameliorative ethnonyms are used represent peculiar interest due to the "plasticity" — the core feature of ethnicity. The article deals with the discourses affecting changes in interlocutors' behaviour in communicative situations (both interpersonal and intergroup encounter are considered). The communicative situations are studied through the analysis and interpretation of the pragmatic potential of ethnic considerations favorable for both partners. The orientational influence exercised by the ethnic names is under consideration. The particular attention is drawn to the vector of ethnicity development typical of each participant.
\end{abstract}

В современном многонациональном мире необходимы исследования этнической идентичности, равно как ее роли в развитии и самоутверждении личности, способности индивида устанавливать отношения с другими людьми, как с представителями других этногрупп, так и своей этногруппы (этнофорами), а также способности управлять этими отношениями.

Изменившийся за последние годы практически до неузнаваемости мир со всем многообразием межличностных и международных отношений все чаще обращает взгляды ученых на этничность человека, как представи- 
теля некоторой национальности, и этничность целого народа, как многомерное ощущение и чувство принадлежности определенной социальной группе. Изучение и обсуждение феномена этнической идентичности традиционно проводятся в рамках научных исследований [1-3]. В стремлении ответить на вопросы, что такое этническая идентичность, какова природа ее формирования и оформления, нередко ускользает главный вопрос, являющийся целью этих обсуждений: «Зачем знать, что такое этническая идентичность, и как этим знанием пользоваться?».

В то же время прагматический потенциал этнолингвистических и этнопсихологических знаний трудно переоценить: во-первых, понимание сути этничности позволит значительно быстрее анализировать межнациональные и межгрупповые процессы (под межгрупповыми процессами в данном контексте понимаются межэтнические взаимодействия) с целью своевременного построения эфффективной поведенческой реакции в возникшей коммуникативной ситуации; во-вторых, такие знания будут способствовать более основательному изучению причин межличностных столкновений представителей разных национальностей и долговременных международных конфрликтов, которые приобрели особую остроту в последние десятилетия.

Данное исследование представляет собой попытку выделить наиболее важные параметры этнической идентичности: условия формирования, проявления (реализации), изменения (если такое возможно); позволяет попробовать на конкретных дискурсивных примерах показать пользу «замера» этнических параметров для ориентирования в ситуации межэтнического взаимодействия.

Исследование, основанное на обобщенных данных из разных областей науки: биологии, психологии, фрилософии, этнологии и политологии, с целью установления сущности категории этнической принадлежности, а также анализ этнонимов и разнообразной лингвистической иноормации позволяют заключить, что этничность - это, прежде всего, культурно-генетическая принадлежность индивида к тому или иному этносу, форма субъективной связи с ним, мера включенности личности в этническую систему, формируемая и проявляющаяся в процессе социализации [4]. Кроме того, этничность особое устойчивое (хотя различное по интенсивности) эмоционально-психическое переживание групповой солидарности, фрормирующееся на основе биосоциального единства, развивающееся в процессе социализации, проявляющееся в межгрупповом взаимодействии в форме противопоставления «своих» и «других" в этносоциальном пространстве и выполняющее жизненно необходимые для живой системы (отдельного индивида, группы, общества) фрункции межсубъективного, внутри-и внешнегруппового ориентирования [4].

Из приведенных определений следует несколько важных для международного и межличностного общения тезисов:

- этническая группа представляет собой биосоциокультурный конструкт, форму проявления жизнедеятельности организма, реализующую защитную и регулятивную функции;

- этничность, как и разные варианты ее проявления, прежде всего использование в коммуникативном взаимодействии этнонимических выражений, есть вид актуализации инстинкта самосохранения живой системы;

- этническая идентичность выполняет защитную и регулятивную функции в групповых взаимодействиях на личностном, межличностном и индивидуально-групповом уровнях;

- этничность имеет феноменологический характер, проявляется в конкретной речевой ситуации с учетом ее особенностей, и, прежде всего, участников.

Анализ теоретического и практического материала (под последним понимается исследование контекстов, основанное на анализе вербального и невербального поведения индивидов, в которых проявляется этническая принадлежность) показал, что условия формирования этнической идентичности есть суть ее реализации, т. е. для того, чтобы почувствовать себя представителем некоторой этногруппы, необходимо иметь опыт столкновения ${ }^{1}$ с представителем другой этногруппы и приобрести опыт солидарности, пережить чувство единения с этнофрорами.

Иными словами, этничность включает взаимодействие между внутренним миром отдельной личности и чувством индивидуальности в процессе жизни в обществе, в ходе чего происходит усвоение его культурных норм, осуществляется идентификация человека. Этническая идентичность является не конечной, а переменной величиной. Она может быть зафиксирована в каждой конкретной ситуации меж- или внутринационального

Под столкновением понимается ситуация, при которой наблюдается расхождение каких-либо интересов (либо актуализация отторженияилинеприязни к другой этничности) двух и более взаимодействующих сторон, либо происходит реализация этнической принадлежности каждой из них. 
взаимодействия, но полученные «замеры» в своей совокупности едва ли могут служить основанием для фоорирования вектора ее развития. Этничность, независимо от того, рассматривается ли она в разрезе индивидуального или коллективного взаимодействия, обладает свойством «пластичности», т. е. она способна подвергаться временным и ситуативным трансорормациям [4; 5]. Эта характеристика этничности является, пожалуй, одной из главных ее особенностей. На практике это качество проявляется в непостоянстве «заряда» отношений между индивидами, а иногда и государствами: сегодня положительные, завтра они могут смениться нейтральными или вовсе приобрести отрицательный «заряд». Факторы, оказывающие влияние на такие изменения, многочисленны и разнообразны. К наиболее значимым факторам в области внутри- и межнационального общения относятся социальные реформы и перестройки, дипломатические отношения, реализация некоторого политического курса; на уровне межличностного взаимодействия такими факторами могут быть бытовые конфликты, дискурсивные недопонимания и недоразумения, явное или скрытое столкновение интересов двух и более сторон. Этничность выполняет в жизни индивида и социума ориентирующую и адаптивную функции, а «пластичность» способствует гибкости поведения и в целом поддержанию благоприятных условий для их жизнедеятельности.

Однако именно по этой причине, связанной с непостоянством проявления, сам фракт существования этнической идентичности ставится под сомнение. «На протяжении многих лет "этничность" является ключевым понятием социологии и антропологии, но, тем не менее, по-прежнему представляется неясным его значение, применение и соотношение с другими понятиями» [6, с. 1]; этнос «не обнаруживает себя как социальная система, он стихиен, аморфен, неструктурирован... В то же время само этническое "нечто" в обществе, несомненно, субстанционально, активно (порой весьма активно) и значимо» [7, с. 15]. Этничность проявляется повсюду, влияет на любые сферы жизни и деятельность человека, и в то же время это «доопытный, внеопытный принцип организации человечества, ее нельзя ни создать, ни разрушить искусственно, это сверхсоциальная субстанция, неуловимая и бесплотная» $[8$, с. 41].

Так, признавая фракт существования этнической идентичности, ее постоянного обнаружения в ситуациях взаимодействия со "своими» и "чужими»", принимая ее во всем разнообразии проявления (от небрежного хлопка по плечу в дружеской беседе до полемического спора в высоких политических кругах) и контролируя ее природу (отслеживая, прежде всего, запуск и актуализацию адаптивных механизмов), можно выстраивать взаимодействие с собеседниками по пути установления как дружеских, так и враждебных отношений. В настоящей статье внимание сосредоточено на ситуациях эффрективного выстраивания межличностного и межнационального общения, с достижением высокого качества последнего.

Рассмотрим некоторые ситуации, в которых произошла эффрективная реализация прагматического потенциала этнических представлений.

Афрроамериканец Камерон (взрослый образованный мужчина, преуспевающий режиссер) и его жена были унижены офицером полицейской службы. Конфликт возник на почве предубеждения полицейского в отношении представителей черной расы. На следующий день Камерон на съемках своего фильма замечает, что в одном из эпизодов темнокожий актер Эдди произносит реплику не на сленге темнокожих подростков, а на нормативном английском языке. После произошедшего накануне инцидента Камерон находится в бунтарском настроении и игнорирует ошибку, допущенную актером. Однако присутствующий на площадке продюсер заострил внимание режиссера на недочете:

«Have you noticed that he's talking a lot less black lately»?

"You mean the audience won't recognize him as being a black man»?

«Is there a problem, Cameron»?

«Excuse me»?

«No, we don't have a problem».

"All I'm saying is that it's not his character. Eddie's supposed to be the smart one - not Jamal. Right? You're the expert here, but to me it rings false ${ }^{3}$.

Продюсер знает Камерона как требовательного профессионального режиссера и уравновешенного человека. Поэтому по имплицитному отказу режиссера от полного соответствия персонажа ожидаемым требованиям он понимает, что у Камерона что-то случилось, о чем он аккуратно интересуется у партнера. Возможно, предполагая, что настроение Камерона вызвано проблемой, связанной с этно-расовыми взглядами,

2 Подробнее о дихотомии «свой» - «чужой» см. Т. Г. Стефаненко, Ю. М. Лотман [9; 10].

${ }^{3}$ URL: http: / / www.subtitles.com. 
продюсер четко фрормулирует свое мнение по поводу съемок; при этом он не пренебрегает мнением режиссера, а, наоборот, подчеркивает его авторитет.

Другой пример эфффективного вербального поведения в контексте этно-национального взаимодействия представляет собой диалог школьного врача и темнокожего студента, которые коснулись темы отношения учителей к расовому вопросу, их мнения об афроамериканских студентах:

"Our teacher says we're supposed to be colorblind. That's hard to do if you can see color, isn't it»?

"Yeah, I'd say so, but I think your teacher means don't make any assumptions based on color".

"Cross on the green and not in between».

"They're talking about human color».

«So»?

"So just pretend that you don't see color. Don't say things like "Black people are lecherous, violent, natural-born criminals".

«But I'm black».

«Oh, I hadn't noticed» [11, c. 167].

В данном отрывке вопреки стереотипной ситуации, где темнокожие люди болезненно воспринимают акцентированное внимание на их расе, афроамериканский мальчик признает свою расовую принадлежность. Он не понимает, почему учителя пропагандируют идею игнорирования этно-расовой принадлежности. Доктор, в свою очередь, убеждает мальчика в равенстве людей, предлагает «притворяться, что цвет кожи не имеет значения». Из его слов становится понятно, что он признает фракт неравенства темнокожих и белых, но в знак солидарности с преподавателями колледжа и в подтверждение озвученной личной позиции («не судить о людях по цвету кожи») он говорит, что вообще не заметил, что его пациент темнокожий.

Не оправдывая употребления в речи оскорбительных этнонимов, но признавая фракт их биосоциокультурного значения [4], считаем правильным использование в речи обидных выражений с целью психоэмоциональной разрядки, но не в присутствии адресата. В качестве примера можно привести реплику мужчины, адресованную соседям-пакистанцам, которые поздно ночью мешают ему громкими разговорами: «Now maybe some of us, who have to work in the morning, can get a decent night's kip! Bloody Pakis» [11, c. 167].

Оскорбительное «Bloody Pakis», адресованное соседям, не было сказано так громко, как другие слова (значимые слова выделены курсивом): способствовало эмоциональной разрядке говорящего, в то же время не привело к моментальному столкновению, вызванному сказанным уничижительным этнонимом.

Интересный пример на рассматриваемую тему представляет фрагмент выступления президента Российской Федерации В. В. Путина на Международном форуме «Арктика - территория диалога», который состоялся 30 марта 2017 г. в Архангельске. На пленарном заседании в качестве спикеров выступали, помимо российского президента, финский глава государства С. Ниинисте и президент Исландии Г. Йоуханнессон. В процессе выступления президент Финляндии, взяв слово, отметил, что раз уж все констатируют наличие трений, то Арктика с ее климатом - лучшее место, чтобы разрядить обстановку, ведь холод очень успокаивает, на что российский лидер пошутил: «Это нам говорят горячие финские парни. Надо прислушаться». В то же время интересна последовавшая за этим диалогом реплика президента Исландии Г. Йоуханнессон: «Мы тоже крутые холодные исландские парни. У нас маленькая, но гордая страна...» ${ }^{4}$.

Апеллирование к характерной национальной черте финнов не повлекло негативных последствий (межличностного непонимания коннотации этнолексемы, восприятия реплики как личного или группового оскорбления, но подчеркнуло уважительное отношение В. В. Путина к этнической особенности партнера), равно как и пользу, выявленную из ее актуализации в ситуации коммуникативного взаимодействия. Реплика президента Исландии, в свою очередь, подразумевала указание на наличие точек соприкосновения и повод для дружеских партнерских отношений, несмотря на то, что акцент был сделан на этнической характеристике национальности.

Анализ 1500 контекстов использования этнонимов и прочих способов апеллирования к этничности другого, равно как рассмотренные примеры, иллюстрируют «эфффективное ориентирование» участников взаимодействия. Под «эффрективным ориентированием» понимается не только успех в избегании конфрликта на национальной почве, но и достижение такого уровня взаимопонимания, при котором возможно обоюдное обогащение опыта всех участников взаимодействия посредством закрепления имеющихся (положительных или отрицательных) этнопредставлений и (или) преобразования

${ }^{4}$ URL: http://www.m.region29.ru. 
имеющихся представлений об этничности другого. Отметим, что абсолютное благоприятное ориентирование возможно в случае оформления положительного эффректа от приобретенного опыта в долгосрочной реализации, т. е. речь идет о тех случаях, когда участникам межэтнического взаимодействия удалось, подчеркнув разницу между национальностями, найти точки соприкосновения, тот общий интерес, который будет «питать» процесс развития отношений. Важным также представляется тот фракт, что реализованные сиюминутно, эти этнонациональные представления нередко возводятся в абсолют. Оказывающие воздействие на развитие межнациональных или межличностных отношений положительные представления (равно как и негативные мнения о других этносах и национальностях) с трудом подвергаются трансформации спустя время, что способствует формированию стереотипов и предубеждений [4]. Это, в свою очередь, указывает на необходимость оформления научно-исследовательской методики, с помощью которой станет возможным определение степени «пластичности» этничности, ее постоянства и изменчивости, силы проявления, а также параметров «замера» этнической принадлежности (степени лояльности, выраженности чувства принадлежности "своим», спектра фракторов, модифицирующих толерантность по отношению к «своим» и «чужим»и т. д.).

Знания участников межкультурного общения о сложившихся межнациональных представлениях (в том числе межэтнических предубеждениях, стереотипах) играют не последнюю роль в эфрфективном предупреждении конфлликов, а корректный «замер» этих представлений и их использование способствуют благоприятному разрешению проблемных ситуаций.

Исследование ситуаций межэтнического взаимодействия имеет как научное, так и прикладное значение: анализ контекстов проявления этнической идентичности расширяет знания об этничности как таковой, позволяет, используя эти знания на практике, управлять поведенческими и психоэмоциональными процессами в межнациональном взаимодействии. В то же время индивидуальный опыт обогащает коллективное понимание собственной этничности, национальной принадлежности другой группы и в целом помогает углубить представление о феномене «этническая идентичность», ее воздействии на жизнь международного сообщества.

\section{СПИСОК ИСПОЛЬЗОВАННОЙ ЛИТЕРАТУРЫ}

1. Пиаже Ж. Речь и мышление ребенка : пер. с фр. / Ж. Пиаже. - М. : Педагогика, 1994. - 527 с.

2. Эриксон Э. Идентичность: Юность и кризис : пер. с англ. / Э. Эриксон. - М. : Прогресс, 1996. - 344 с.

3. Гумилев Л. Н. Этногенез и биосфера Земли / Л. Н. Гумилев. - М. : АСТ, 2002. - 560 с.

4. Шастина И. А. Языковая категоризация этнической принадлежности (когнитивно-аксиологический аспект) : дис. ... канд. фрилол. наук : 10.02.19 / И. А. Шастина. -Иркутск, 2008. - 236 с.

5. Губогло М. Н. Идентификация идентичности : этносоциол. очерки / М. Н. Губогло. - М. : Наука, 2003. $-764 \mathrm{c}$.

6. Banks M. Ethnicity: Anthropological Constructions / M. Banks. - London : Routledge, 1996. $-210 \mathrm{p}$.

7. Рыбаков С. Е. Судьбы теории этноса. Памяти Ю. В. Бромлея / С. Е. Рыбаков / / Этнографическое обозрение. - 2001. - № 1. - С. 3-22.

8. Чешко С. В. Человек и этничность / С. В. Чешко // Этнографическое обозрение. - 1994. — № 6. C. $35-43$.

9. Стефаненко Т. Г. Этнопсихология / Т. Г. Стефраненко. - М. : Ин-т психологии РАН : Акад. проект, 2000. $-320 \mathrm{c}$.

10. Лотман Ю. М. Семиосфера : Культура и взрыв ; Внутри мыслящих миров ; Статьи ; Исследования ; Заметки / Ю. М. Лотман. - СПб. : Искусство-СПб., 2000. - 703 с.

11. Smith Z. White Teeth / Z. Smith. - New York: Vintage Books, 2001. - 144 p.

\section{REFERENCES}

1. Piaget J. Rech' i myshlenie rebenka [The Language and Thought of the Child]. Moscow, Pedagogika Publ., 1994. $527 \mathrm{p}$.

2. Erikson E. Identity: Youth and Crisis. New York, W.W. Norton \& Company o Inc., 1968. (Russ. ed.: Erikson E. Identichnost': yunost' i krizis. Moscow, Progress Publ., 1996. 344 p.).

3. Gumilev L. N. Etnogenez i biosfera Zemli [Ethnogenesis and the Biosphere of Earth]. Moscow, AST Publ., 2002. 560 p.

4. Shastinal. A. Yazykovaya kategorizatsiya etnicheskoi prinadlezhnosti (kognitivno-aksiologicheskiy aspekt). Kand. Diss. [Linguistic Categorization of Ethnicity (the Cognitive-Axiological Aspect). Cand. Diss.]. Irkutsk, 2008. 236 p.

5. Guboglo M. N. Identifikatsiya identichnosti: etnosotsiologicheskie ocherki [Identification of Identity: EthnoSociological Essays]. Moscow, Nauka Publ., 2003. 764 p.

6. Banks M. Ethnicity: Anthropological Constructions. London, Routledge, 1996. 210 p. 
7. Rybakov S. E. The Fate and Fortunes of the Ethnos Theory. In memory of Yulian Bromley. Etnograficheskoe obozrenie = Ethnographic Survey, 2001, no. 1, pp. 3-22. (In Russian).

8. Cheshko S. V. Man and Ethnicity. Etnograficheskoe obozrenie = Ethnographic Survey, 1994, no. 6, pp. 3543. (In Russian).

9. Stefanenko T. G. Etnopsikhologiya [Ethnopsychology]. Moscow, Institute of Psychology of Russian Academy of Sciences Publ., Akademicheskii proekt Publ., 2000. 320 p.

10. Lotman Yu. M. Semiosfera [Semiosphere]. Saint Petersburg, Iskusstvo-SPB Publ., 2000. 703 p.

11. Smith Z. White Teeth. New York, Vintage Books, 2001. 144 p.

\section{Информация об авторах}

Антипьева Ирина Александровна - кандидат филологических наук, доцент, кафедра иностранных языков, Байкальский государственный университет, 664003, г. Иркутск, ул. Ленина, 11, e-mail: shastinairina@rambler.ru.

Липко Юлия Георгиевна - кандидат филологических наук, доцент, кафедра гуманитарных дисциплин и иностранных языков, Иркутский государственный университет, 664003, г. Иркутск, ул. Карла Маркса, 1, e-mail: jossjulia@gmail.com.

\section{Для цитирования}

Антипьева И. А. Эффрективная реализация прагматического потенциала этнической идентичности в ситуациях межэтнического взаимодействия / И. А. Антипьева, Ю. Г. Липко // Известия Байкальского государственного университета. - 2017. T. 27, № 3. - C. 327-332. - DOI: 10.17150/25002759.2017.27(3).327-332.

\section{Authors}

Irina A. Antipieva - PhD in Philology, Associate Professor, Foreign Languages Department, Baikal State University, 11 Lenin St., 664003, Irkutsk, Russian Federation, e-mail: shastinairina@rambler.ru.

Yulia G. Lipko - PhD in Philology, Associate Professor, Department of Humanities and Foreign Languages, Baikal International Business School, Irkutsk State University, 1, Karl Marx St., 664003, Irkutsk, Russian Federation, e-mail: jossjulia@gmail.com.

\section{For Citation}

Antipieva I. A., Lipko Yu. G. Pragmatic Potential of Ethnic Identity and Its Effective Realization in International Interaction. Izvestiya Baykal'skogo gosudarstvennogo universiteta $=$ Bulletin of Baikal State University, 2017, vol. 27, no. 3, pp. 327-332. DOI: 10.17150/25002759.2017.27(3).327-332. (In Russian). 